\title{
Effect of Single-Injection Thoracic Paravertebral Block via the Intrathoracic Approach for Analgesia After Single-Port Video-Assisted Thoracoscopic Lung Wedge Resection: A Randomized Controlled Trial
}

\author{
Lihong $\mathrm{Hu}$ (D) Xia Xu $\cdot$ Hui Tian $\cdot$ Jinxian He
}

Received: November 16, 2020 / Accepted: December 18, 2020 / Published online: January 9, 2021

(c) The Author(s) 2021

\begin{abstract}
Introduction: Pain is still severe after singleport video-assisted thoracoscopic (SPVAT) lung wedge resection. We observed the effect of single-injection thoracic paravertebral block (TPB) via the intrathoracic approach for analgesia after SPVAT lung wedge resection.

Methods: Sixty patients undergoing SPVAT lung wedge resection were randomly divided into a control group and an observation group. All patients underwent TPB via the intrathoracic approach at the T4 level with a scalp needle before closing the chest. The patients in the observation group received $20 \mathrm{ml} 0.375 \%$ ropivacaine at the T4 level, and the patients in the control group received $20 \mathrm{ml}$ of $0.9 \%$ saline. A patient-controlled intravenous analgesic (PCIA) pump with sufentanil was attached to all patients after surgery. The sufentanil consumption and number of PCIA presses in the first $24 \mathrm{~h}$ after surgery were recorded. The visual
\end{abstract}

Supplementary Information The online version contains supplementary material available at https:// doi.org/10.1007/s40122-020-00231-y.

L. Hu $(\bowtie) \cdot X . X u$

Department of Anesthesiology, Ningbo Medical Center Lihuili Hospital, Ningbo, China

e-mail: hlh_2000@163.com

H. Tian · J. He

Department of Thoracic Surgery, Ningbo Medical

Center Lihuili Hospital, Ningbo, China analogue scale (VAS) scores (during rest and coughing) were recorded at $6 \mathrm{~h}, 12 \mathrm{~h}, 24 \mathrm{~h}$, and $36 \mathrm{~h}$ after surgery. The incidence of adverse reactions after surgery were recorded.

Results: The sufentanil consumption in the observation group was significantly lower than that in the control group $(34.2 \pm 1.9 \mu \mathrm{g}$ vs. $52.3 \pm 2.3 \mu \mathrm{g} ; P<0.001)$. The VAS score at 6 , 12 , and $24 \mathrm{~h}$ after surgery, the incidence of adverse reactions after surgery in the observation group were significantly lower than those in the control group (all $P<0.05$ ). The number of PCIA presses in the observation group was significantly lower than that in the control

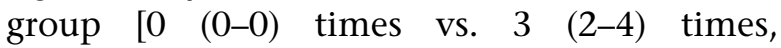
$P<0.001]$.

Conclusions: Single-injection TPB via the intrathoracic approach under thoracoscopic direct vision is easy to perform and can effectively alleviate postoperative pain after SPVAT lung wedge resection, with fewer adverse reactions.

Trial Registration: ChiCTR2000034726.

Keywords: Lung wedge resection; Postoperative analgesia; Single injection; Single-port video-assisted thoracoscopic surgery; Thoracic paravertebral block 


\section{Key Summary Points}

Why carry out this study?

Pain is still severe after single-port thoracoscopic (SPVAT) lung wedge resection.

Can single injection local anesthetics into the paravertebral space via the intrathoracic approach under thoracoscopic direct vision alleviate postoperative pain?

\section{What was learned from the study?}

Single-injection TPB via the intrathoracic approach can alleviate postoperative pain and reduce adverse reactions.

Single-injection TPB via the intrathoracic approach under thoracoscopic direct vision is easy to perform and can effectively alleviate postoperative pain after SPVAT lung wedge resection with fewer adverse reactions.

\section{DIGITAL FEATURES}

This article is published with digital features, including a summary slide, to facilitate understanding of the article. To view digital features for this article go to https://doi.org/10.6084/ m9.figshare.13402367.

\section{INTRODUCTION}

Traditional thoracotomy has great trauma and severe postoperative pain. At present, thoracoscopic minimally invasive surgery is the main method of thoracic surgery $[1,2]$. In recent years, single-port video-assisted thoracoscopic (SPVAT) surgery has been widely used in thoracic surgery $[3,4]$, especially in lung wedge resection [5]. SPVAT lung wedge resection has the advantages of less incision, less pain and faster recovery. It was considered to have mild postoperative pain, and ignored the need for postoperative analgesia, resulting in insufficient analgesic measures after surgery. In fact, the postoperative pain is still severe, which seriously affects the patient's postoperative recovery [6]. Currently, postoperative analgesia after thoracic surgery mainly includes thoracic epidural analgesia, patient-controlled intravenous analgesic (PCIA), thoracic paravertebral block (TPB) and erector spinae plane block [7]. These are mainly performed by well-trained anesthesiologists, and are mainly used in radical cancer surgery and other thoracic surgery. With the popularization of the concept of enhanced recovery after surgery, the surgical team began to pay attention to postoperative pain management. In recent years, percutaneous catheter TPB or intercostal nerve block under thoracoscopic direct vision has been widely favored by surgeons $[8,9]$. The various analgesic methods mentioned above have their own advantages, but also have many complications and disadvantages [10-16]. Is there a simpler, quicker, effective and less complication analgesic method that can be used for postoperative analgesia after SPVAT lung wedge resection? Is it possible to inject local anesthetics(LAs) directly into the paravertebral space via the intrathoracic approach under thoracoscopic direct vision to achieve the purpose of $\mathrm{TPB}$, thereby reducing postoperative pain? There is no report about it. Therefore, this study explored the analgesic effect of single-injection TPB via the intrathoracic approach under thoracoscopic direct vision for analgesia after SPVAT lung wedge resection.

\section{METHODS}

\section{Patients}

This study was approved by the Ethics Committee of Ningbo Medical Center, Lihuili Hospital, China (approval reference: KY2020PJ015). The study was performed in accordance with the Helsinki Declaration of 1964 and its later amendments. All participants provided informed consent to participate in the study. The trial was registered at www.chictr. 

$\begin{array}{llr}\text { org.cn number: } & \text { (registration } \\ \text { ChiCTR2000034726). Sixty patients undergoing }\end{array}$ SPVAT lung wedge resection were enrolled between July 2020 and October 2020 in the Ningbo Medical Center Lihuili Hospital. The inclusion criteria for patients were as follows: age between 18 and 65 years, an American Society of Anesthesiologists (ASA) physical status of I II, pneumothorax and bullae or lung nodules considered carcinoma in situ with a requirement for minimally invasive surgery. The exclusion criteria were patients with spinal deformity or spinal surgical history, allergies to LAs, and patients who did not consent to the procedure.

Patients were randomized divided into a control group and an observation group using a computer-generated random table, which was performed by an investigator who not involved in patient perioperative care and data collection. The investigator informed a nurse to prepare $20 \mathrm{ml}$ of $0.375 \%$ ropivacaine or normal saline. Patients, surgeons, anesthesiologists, data acquisition personnel did not know the grouping.

\section{Anesthesia}

Standard monitoring was performed for electrocardiogram, blood pressure, heart rate, and oxygen saturation when the patients entered the operating theater. Rapid intravenous induction with $0.05 \mathrm{mg} / \mathrm{kg}$ midazolam, $0.2 \mu \mathrm{g} /$ $\mathrm{kg}$ sufentanil, $2 \mathrm{mg} / \mathrm{kg}$ propofol, and $0.6 \mathrm{mg} / \mathrm{kg}$ rocuronium was performed. After tracheal intubation, a bronchial occluder was optimally positioned using fiberoptic bronchoscope guidance. Mechanical Ventilation was given to ensure a tidal volume of $6 \mathrm{ml} / \mathrm{kg}$, and a respiratory rate of $10-12$ times/min. The intraoperative anesthesia maintenance was $8 \mathrm{mg} \cdot \mathrm{kg}^{-1}$ $\mathrm{h}^{-1}$ propofol, $0.1 \mu \mathrm{g} \mathrm{kg}^{-1} \mathrm{~min}^{-1}$ remifentanil, and $0.2 \mathrm{mg}(\mathrm{kg} 0.5 \mathrm{~h}$ ) rocuronium with a single intravenous injection. Adjusted the dose of the anesthetic to maintain the bispectral index between 45 and 55 .

\section{Surgery}

A 4-cm incision was made between the four and five intercostals in the axillary midline of the two groups. SPVAT lung wedge resection was performed. The pulmonary nodules were confirmed as benign tumor or carcinoma in situ by intraoperative pathology.

\section{Analgesia Methods}

In the observation group, a scalp needle with an extended tube was inserted into the paravertebral space at the T4 level under thoracoscopic direct vision before closing the chest (Fig. 1). One centimeter adjacent to the vertebrae were inserted vertically $0.5 \mathrm{~cm}$ under the parietal pleura with the needle (Fig. 2), and $20 \mathrm{ml}$ $0.375 \%$ ropivacaine was injected. The control group was injected with the same volume of $0.9 \%$ saline at T4 level. Observed for $5 \mathrm{~min}$ to make sure there was no hemorrhage or hematoma. The two groups were given $0.2 \mu \mathrm{g} / \mathrm{kg}$ sufentanil and $2 \mathrm{mg}$ tropisetron $10 \mathrm{~min}$ before the end of surgery. At the end of the surgery, the PCIA pump was connected to patients to administer $1.5 \mu \mathrm{g} \cdot \mathrm{kg}^{-1}$ sufentanil and $5 \mathrm{mg}$ tropisetron diluted to $100 \mathrm{ml}$ with normal saline. The parameters were set as a continuous dose of $2 \mathrm{ml} / \mathrm{h}$, a bolus dose of $1 \mathrm{ml}$, and a locking time of $20 \mathrm{~min}$.

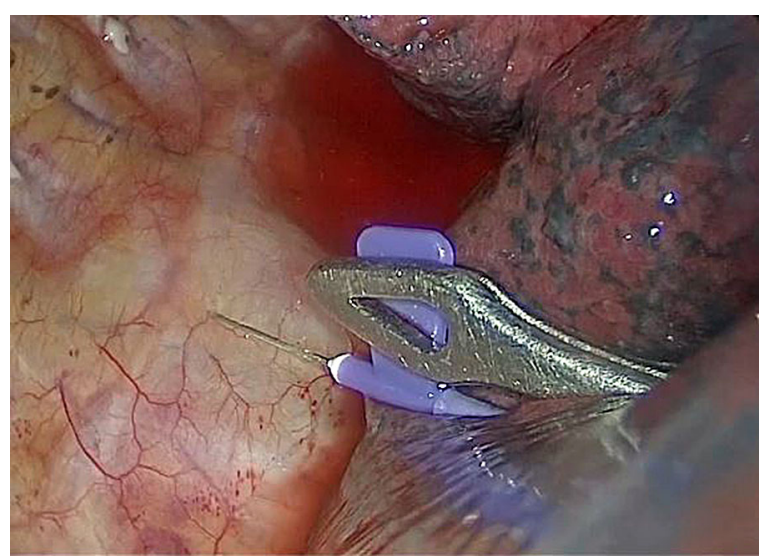

Fig. 1 TPB at T4 level via intrathoracic approach under thoracoscopic direct vision 


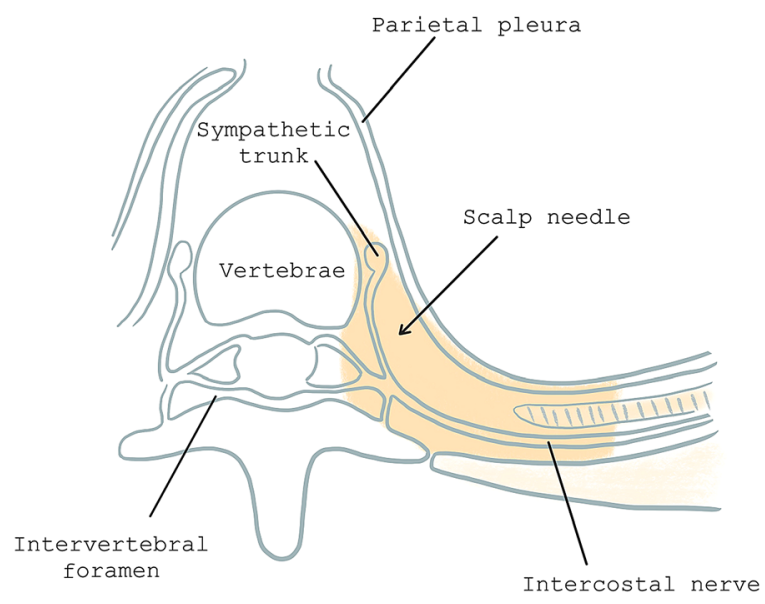

Fig. 2 Horizontal plane of paravertebral space. The orange area represents paravertebral space and site of scalp needle puncture

\section{Data Collection}

The primary outcome was the sufentanil consumption infused by the PCIA in the first $24 \mathrm{~h}$ after surgery. The secondary outcome was the visual analogue scale (VAS) during rest and while coughing at $6,12,24$, and $36 \mathrm{~h}$ after surgery. The number of PCIA presses in the first $24 \mathrm{~h}$ after surgery were recorded. The incidence of adverse reactions such as nausea, vomiting, pruritus, somnolence, and atelectasis were recorded after surgery. The dermatomes of the sensory block were assessed $2 \mathrm{~h}$ after surgery using pinprick in the observation group.

\section{Sample Size}

The primary outcome was the sufentanil consumption infused by the PCIA in the first $24 \mathrm{~h}$ after surgery. Pilot testing using ten patients showed a mean [standard deviation] sufentanil consumption of 37.5 [4.66] $\mu \mathrm{g} 24 \mathrm{~h}$ after surgery in the observation group and 43.5 [5.65] $\mu$ g in the control group. The requirement was 24 patients (12 in each group), which was calculated by the MedSci Sample Size Tools at a power of 0.8 with 0.05 alpha. Thus, to compensate for the possibility of missing data or dropouts, 30 patients were recruited for each group.

\section{Statistical Analysis}

Data were analyzed using SPSS version 23.0 (IBM Corp. Armonk, NY, USA). Continuous variables conforming to the features of normal distribution were represented as mean \pm standard deviation and analyzed using the $t$ test. Repeated measurement data were analyzed using repeated ANOVA. Variables with a skewed distribution were presented as medians (quartiles) and were compared using the Kruskal-Wallis $H$ test. Categorical data were presented as numbers (percentage) and analyzed using the Chi-square $\left(\chi^{2}\right)$ test. In all analyses, $\quad P<0.05$ was considered statistically significant.

\section{RESULTS}

A total of 60 patients were included and completed the study. All patients had successfully performed SPVAT lung wedge resection (Fig. 3). There were no significant differences of the patients' characteristics and surgical parameters between the two groups (Table 1).

\section{Primary Outcome}

The sufentanil consumption within the first $24 \mathrm{~h}$ after surgery in the observation group was significantly lower than that in the control group $\quad(34.2 \pm 1.9 \mu \mathrm{g} \quad$ vs. $52.3 \pm 2.3 \mu \mathrm{g}$; $P<0.001$ ) (Fig. 4).

\section{The Second Outcome}

The VAS scores during rest and coughing at 6 , 12 and $24 \mathrm{~h}$ were significantly lower than that at $36 \mathrm{~h}$ after surgery in the observation group. There was no significant difference in the VAS scores of rest and coughing at each time point in the control group. The VAS scores during rest and coughing in the observation group were significantly lower than those in the control group at 6,12 , and $24 \mathrm{~h}$ after surgery. There was no significant difference in VAS scores between the two groups at $36 \mathrm{~h}$ after surgery (Table 2). 


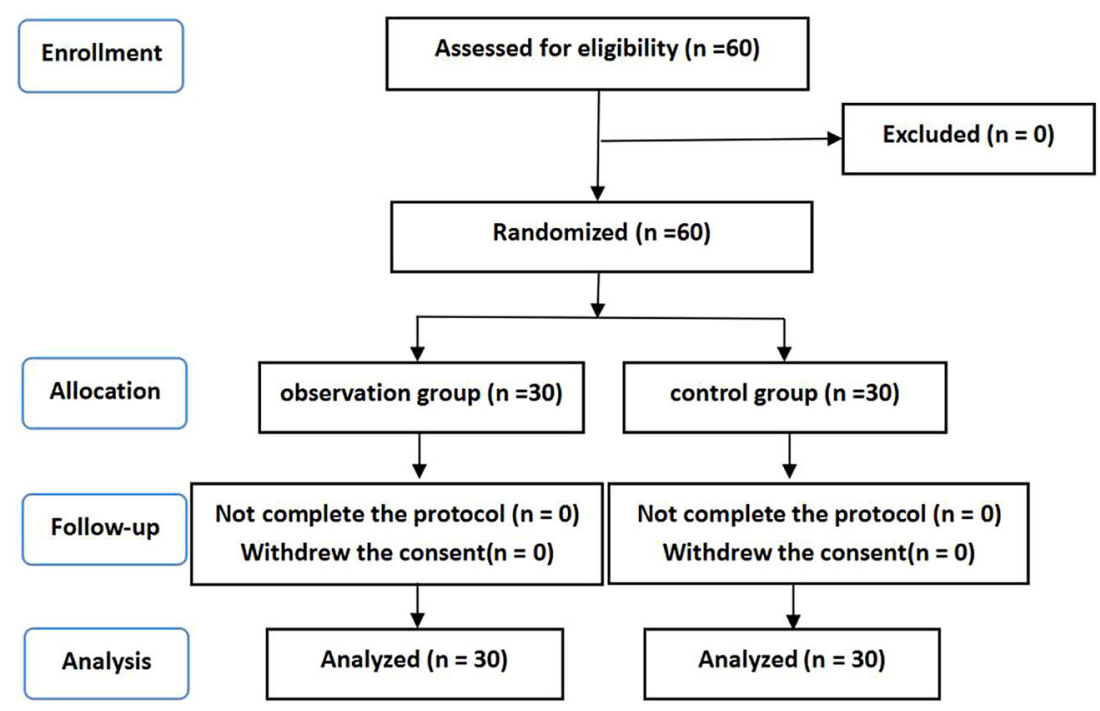

Fig. 3 Flow diagram of study

Table 1 Characteristics and surgical parameters

\begin{tabular}{llll}
\hline & Control group $(\boldsymbol{n}=\mathbf{3 0})$ & Observation group $(\boldsymbol{n}=\mathbf{3 0})$ & $\boldsymbol{P}$ value \\
\hline Number of patients & 30 & 30 & 0.787 \\
Type of disease & & 11 & \\
Pulmonary bulla or pneumothorax & 10 & 19 & 0.796 \\
Pulmonary nodules & 20 & & \\
Surgical site & & $15(50.0 \%)$ & \\
Left & $16(53.3 \%)$ & $15(50.0 \%)$ & 0.795 \\
Right & $14(46.7 \%)$ & & \\
Gender & & $16(53.3 \%)$ & 0.100 \\
Male & $17(56.7 \%)$ & $14(46.7 \%)$ & 0.115 \\
Female & $13(43.3 \%)$ & $43.5 \pm 11.9$ & 0.765 \\
Age (y) & $48.9 \pm 12.9$ & $62.7 \pm 7.1$ & \\
Weight (kg) & $65.4 \pm 6.1$ & $25.2 \pm 5.7$ & \\
Surgery time (min) & $24.8 \pm 4.5$ & & \\
\hline
\end{tabular}

Data are presented as mean \pm standard deviation or number (\%)

The observation group pressed the PCIA pump [0 (0-0) times] less than the control group [3 (2-4) times] $(P<0.001)$. The incidence of postoperative adverse reactions such as nausea and vomiting in the observation group were significantly lower than those in the control group. No significant differences in the incidences of pruritus, somnolence, and atelectasis were observed between the two groups (Table 3). The dermatomes of the sensory block 


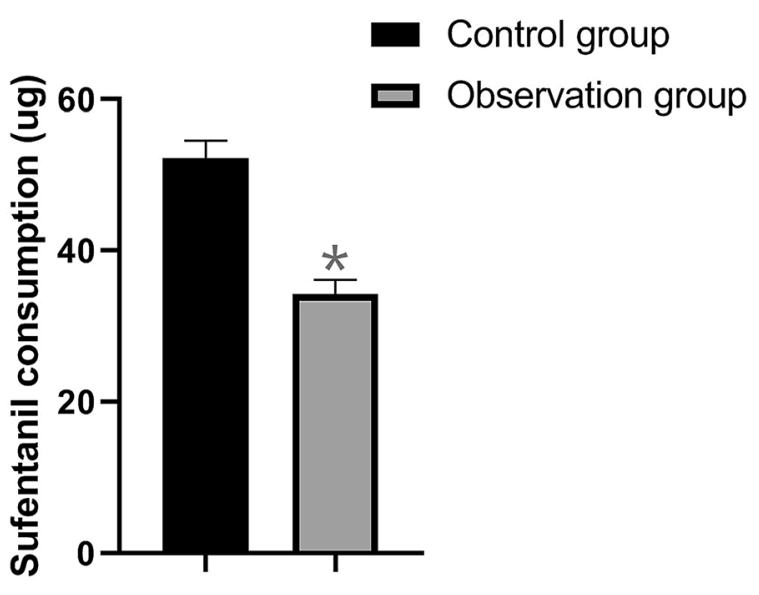

Fig. 4 Sufentanil consumptions within the first $24 \mathrm{~h}$ after surgery of the observation group and control group. ${ }^{*} P<0.001$

in the observation group were maintained at T1-T8 levels, and the main blocking area was at T2-T7 levels with 19 (63.3\%) patients (Fig. 5).

\section{DISCUSSION}

Patients undergoing thoracic surgery have decreased postoperative lung function reserves. The severe pain after surgery prevents patients from breathing deeply with active coughing and sputum, resulting in the retention of respiratory secretions, causing hypoxemia, pneumonia, atelectasis, and even respiratory failure [17]. Adequate postoperative analgesia is conducive to early active cough and sputum discharge, improve lung function, reduce postoperative complications, and promote postoperative recovery. SPVAT lung wedge resection has the advantages of less incision, shorter surgery time, less pain, and faster recovery. Therefore, the management of perioperative pain is often ignored, but in fact, the postoperative pain is still severe, which affects postoperative recovery $[5,18]$. Currently, the commonly used postoperative analgesia is cumbersome and has many complications, and

Table 2 The VAS score after surgery

\begin{tabular}{|c|c|c|c|}
\hline & Control group $(n=30)$ & Observation group $(n=30)$ & $P$ value \\
\hline \multicolumn{4}{|l|}{ During rest } \\
\hline $6 \mathrm{~h}$ after surgery & $3.5 \pm 0.7$ & $2.5 \pm 0.3$ & $<0.001^{*}$ \\
\hline $12 \mathrm{~h}$ after surgery & $3.4 \pm 0.7$ & $2.5 \pm 0.2$ & $<0.001^{*}$ \\
\hline $24 \mathrm{~h}$ after surgery & $3.4 \pm 0.7$ & $2.4 \pm 0.2$ & $<0.001^{*}$ \\
\hline $36 \mathrm{~h}$ after surgery & $3.2 \pm 0.6$ & $3.2 \pm 0.5$ & 0.805 \\
\hline$F$ value & 1.0 & 82.0 & \\
\hline$P$ value & 0.318 & $<0.001^{\#}$ & \\
\hline \multicolumn{4}{|l|}{ While coughing } \\
\hline $6 \mathrm{~h}$ after surgery & $4.5 \pm 0.4$ & $3.1 \pm 0.3$ & $<0.001^{*}$ \\
\hline $12 \mathrm{~h}$ after surgery & $4.8 \pm 0.3$ & $3.0 \pm 0.3$ & $<0.001^{*}$ \\
\hline $24 \mathrm{~h}$ after surgery & $4.6 \pm 0.3$ & $3.0 \pm 0.3$ & $<0.001^{*}$ \\
\hline $36 \mathrm{~h}$ after surgery & $4.4 \pm 0.4$ & $4.5 \pm 0.4$ & 0.637 \\
\hline$F$ value & 2.1 & 182.8 & \\
\hline$P$ value & 0.154 & $<0.001^{\#}$ & \\
\hline
\end{tabular}

Data are presented as mean \pm standard deviation, ${ }^{*} P<0.001$ Observation group vs Control group, ${ }^{\#} P<0.00136 \mathrm{~h}$ after surgery vs $6 \mathrm{~h}, 12 \mathrm{~h}$, and $24 \mathrm{~h}$ after surgery 
Table 3 The incidence of adverse reactions after surgery

\begin{tabular}{llll}
\hline & Control group $(\boldsymbol{n}=\mathbf{3 0})(\%)$ & Observation group $(\boldsymbol{n}=\mathbf{3 0})(\%)$ & $\boldsymbol{P}$ value \\
\hline Nausea & $12(40.0 \%)$ & $3(10.0 \%)$ & $0.007^{*}$ \\
Vomit & $9(30.0 \%)$ & $2(6.7 \%)$ & $0.020^{*}$ \\
Pruritus & $4(13.3 \%)$ & $0(0.0 \%)$ & 0.121 \\
Somnolence & $3(10.0 \%)$ & $0(0.0 \%)$ & 0.236 \\
Atelectasis & $3(10.0 \%)$ & $1(3.3 \%)$ & 0.605 \\
\hline
\end{tabular}

Data are presented as number $(\%)^{*} P<0.05$

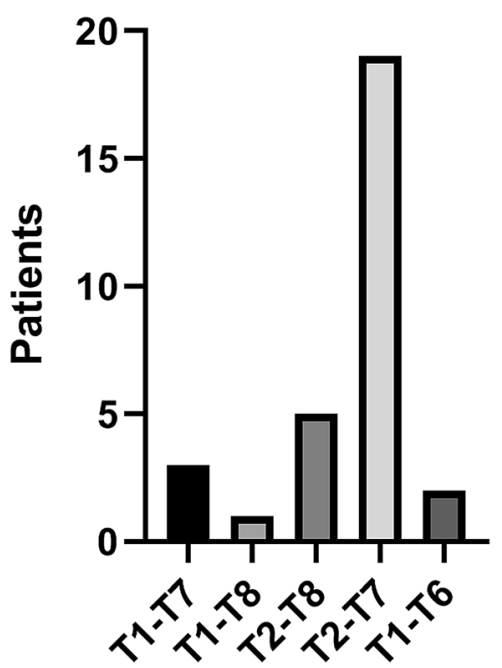

Fig. 5 Dermatomes of the sensory block in the patient of observation group. Frequency of sensory segments blockade to sharp touch at $2 \mathrm{~h}$ later after surgery

lacks a postoperative analgesia suitable for SPVAT wedge resection.

Currently, postoperative analgesia after thoracic surgery mainly includes thoracic epidural analgesia, PCIA, TPB, erector spinae plane block and intercostal nerve block $[7,9,19]$. Thoracic epidural analgesia is the gold standard for postoperative analgesia after thoracic surgery, but there are still complications such as epidural hematoma or infection, nerve damage or hypotension [11-13]. While PCIA is simple and convenient for postoperative care [14], but it requires large amounts of systemic opioids, with the adverse reactions such as nausea and vomiting [15]. TPB is a technique of injecting LAs into the paravertebral space, which produces a similar effect to unilateral epidural block and effectively reduce postoperative pain $[16,20-22]$. However, the requirements for ultrasound imaging and block technology are high, the operation space is limited and the difficulty is greater, the success rate is low. There is a possibility of puncturing the pleura and damaging the intercostal nerve or sympathetic chain $[8,21,23,24]$. Compared with TPB, erector spinae plane block has a higher success rate, but requires higher ultrasound imaging and block technique [19]. Intercostal nerve block has a limited block range and can only suppress incision pain [9]. The above-mentioned analgesia methods require well-trained anesthesiologists, which are cumbersome, have more complications, and have a high failure rate. They are not suitable for SPVAT wedge resection.

Is there a simpler, faster operation, fewer complications, and an effective analgesic method that can apply postoperative analgesia after SPVAT wedge resection? Therefore, this study aimed to investigate the analgesic effect of single-injection TPB via the intrathoracic approach for analgesia after SPVAT lung wedge resection.

In this study, we used single-injection TPB at the T4 level. Before the end of the surgery, the scalp needle with the extended tube was inserted into the paravertebral space at the T4 level under thoracoscopic direct vision. One centimeter adjacent to the thoracic vertebrae were inserted vertically $0.5 \mathrm{~cm}$ under the parietal pleura and $20 \mathrm{ml} 0.375 \%$ ropivacaine was injected. The dermatomes of the sensory block 
in the observation group were maintained at $\mathrm{T} 1-\mathrm{T} 8$, and $19(63.3 \%)$ were at T2-T7, indicating that the LAs was effectively spreading into the paravertebral space. The study by Gacio et al. reported ultrasound-guided single-injection paravertebral block allows proper control of acute pain with less intraoperative and postoperative consumption of opioids in major breast surgery [25]. The sufentanil consumption, VAS score, and number of PCIA presses in the observation group were significantly lower than those of the control group in the first $24 \mathrm{~h}$ after surgery. This fully showed that the postoperative pain of the observation group was significantly reduced, and once again proved that the single-injection TPB under thoracoscopic direct vision was indeed effective and feasible. LAs spread in the paravertebral spaces of 2-4 vertebral planes above and below the T4 segment, basically covering the area of surgery and incision, effectively reducing postoperative pain and reducing the amount of intravenous opioids after surgery. This is similar to the results of Gacio et al. [25]. The duration of the single injection TPB was related to the concentration of the LAs, generally within $12-24 \mathrm{~h}$. The VAS scores during rest and coughing at 6 , 12 , and $24 \mathrm{~h}$ were significantly lower than that at $36 \mathrm{~h}$ after surgery in the observation group. This result also proved once again that the duration of a single block is within $24 \mathrm{~h}$. There was no significant difference in VAS scores between the two groups at $36 \mathrm{~h}$ after surgery. This might be due to the following reasons: (1) SPVAT wedge resection is less traumatic, and the postoperative pain is mainly within $24 \mathrm{~h}$ after the surgery, and the pain is less after $24 \mathrm{~h}$. (2) The endogenous analgesic system is activated when TPB block the transmission of noxious stimuli to the center nervous system at the level of the spinal cord, which can continue to play an analgesic effect. (3) The effect of TPB is gradually subsided, so that the patient's tolerance threshold for pain is increased, and hyperalgesia is avoided. This also suggests that after the effect of a single injection SITPB is over, it may still promote the improvement of postoperative pain through other ways.

Thoracoscopy imaging has magnification function and the thoracic vertebral body and paravertebral tissue were fully exposed after lung atrophy. The vertical distance between the parietal pleura and the intervertebral foramen is about $1.0 \mathrm{~cm}$. This ensures that the LAs is completely injected into the paravertebral space. We chose the transmural pleura to insert the needle vertically at a depth of $0.5 \mathrm{~cm}$ to avoid the risk of damaging the nerve root, or even entering the spinal canal. Single-injection TPB via the intrathoracic approach under thoracoscopic direct vision is easy to operate. It only requires checking the Computer tomography image structure of the block site before the block and it can be completed quickly by the surgeon. Compared with conventional multiports thoracoscopic surgery, SPVAT lung wedge resection has fewer incisions and faster recovery. In this study, a single-injection TPB can meet the need for postoperative analgesia. Compared with the single-injection TPB in this study, the operation of ultrasound-guided TPB or erector spinal plane block was relatively complicated, and the advantages and significance of analgesia after this kind of surgery might not be obvious.

Arunakul et al. found that PVB can reduce postoperative opioid requirement, pain, and severity of nausea and vomiting in modified radical mastectomy [26]. In this study, the incidence of nausea and vomiting in the observation group were significantly lower than those in the control group, which may be due to the poor analgesic effect of the control group, the consumption of sufentanil was more, the use of opioids was larger, so the incidence of adverse reactions was higher. There was no statistical significance of the incidence of pruritus and somnolence between the two groups of patients. This may be because the concentration of opioids is not enough to cause skin pruritus and somnolence. There was no atelectasis in the two groups, which may be due to less lung tissue resection, shorter surgery time and one lung ventilation time.

The present study had several limitations. First, this study did not observe local anesthetic poisoning, high epidural block and other blockrelated complications. Second, this study did not observe pain-related indicators such as sufentanil consumption beyond $24 \mathrm{~h}$ after 
surgery. Lastly, this study did not compare with ultrasound-guided single thoracic paravertebral block or erector spinal plane block in terms of operation time, success rate, sensory level, and complications. These are also our next research directions.

\section{CONCLUSIONS}

In conclusion, a single-injection TPB via the intrathoracic approach under thoracoscopic direct vision is simple and quick to operate, which can effectively reduce postoperative pain after SPVAT wedge resection, with fewer adverse reactions.

\section{ACKNOWLEDGEMENTS}

The authors would like to thank the nurse for preparing ropivacaine or normal saline in this study.

Funding. This study was supported by Science and Technology Innovation 2025 Major Special Project of Ningbo (2019B10039). The funding had no role in study design, data collection, analysis, and interpretation, or preparation of the manuscript. The journal's Rapid Service Fee was funded by the authors.

Authorship. All named authors meet the International Committee of Medical Journal Editors (ICMJE) criteria for authorship for this article, take responsibility for the integrity of the work as a whole, and have given their approval for this version to be published.

Authorship Contributions. LHH conceived and design the study, analyzed the data, and drafted the manuscript; XX, JXH helped collect data. HT, JXH performed the thoracic paravertebral block.

Disclosures. Lihong Hui, Xia $\mathrm{Xu}$, Hui Tian and Jinxian He have nothing to disclose.

Compliance with Ethics Guidelines. This study was approved by Ethics Committee of
Ningbo Medical Center, Lihuili Hospital, China (KY2020PJ015). This study was performed in accordance with the Helsinki Declaration of 1964 and its later amendments. The trial was registered at www.chictr.org.cn (registration number: ChiCTR2000034726). All participants consented to participate in this study and signed informed consent forms.

Data Availability. The data are available from the corresponding author on reasonable request.

Open Access. This article is licensed under a Creative Commons Attribution-NonCommercial 4.0 International License, which permits any non-commercial use, sharing, adaptation, distribution and reproduction in any medium or format, as long as you give appropriate credit to the original author(s) and the source, provide a link to the Creative Commons licence, and indicate if changes were made. The images or other third party material in this article are included in the article's Creative Commons licence, unless indicated otherwise in a credit line to the material. If material is not included in the article's Creative Commons licence and your intended use is not permitted by statutory regulation or exceeds the permitted use, you will need to obtain permission directly from the copyright holder. To view a copy of this licence, visit http://creativecommons.org/licenses/by$\mathrm{nc} / 4.0 /$.

\section{REFERENCES}

1. Leschber G. Video-assisted thoracic surgery: a global development. Chirurg. 2018;89(3):185-90.

2. Fok M, Bashir M, Harky A, et al. Video-assisted thoracoscopic versus robotic-assisted thoracoscopic thymectomy: systematic review and meta-analysis. Innovations (Phila). 2017;12(4):259-64.

3. Bedetti B, Solli P, Lawrence D, et al. Single port video-assisted thoracoscopic thymectomy. J Vis Surg. 2016;2:149.

4. Vieira A, Bourdages-Pageau E, Kennedy K, et al. The learning curve on uniportal video-assisted thoracic 
surgery: an analysis of proficiency. J Thorac Cardiovasc Surg. 2020;159(6):2487-2495.e2.

5. Xu K, Bian W, Xie H, et al. Single-port video-assisted thoracoscopic wedge resection: novel approaches in different genders. Interact Cardiovasc Thorac Surg. 2016;23(2):202-7.

6. Mizukami Y, Takahashi Y, Adachi H. Single-port vs conventional three-port video- assisted thoracoscopic pulmonary wedge resection: comparison of postoperative pain and surgical costs. Ann Thorac Cardiovasc Surg. 2020. https://doi.org/10.5761/ atcs.oa.20-00142.

7. Low DE, Allum W, De Manzoni G, et al. Guidelines for perioperative care in esophagectomy: enhanced recovery after surgery (ERAS) society recommendations. World J Surg. 2019;43:299-330.

8. van den Berg JW, Kate T, Edward C. Paravertebral catheter analgesia for minimally invasive Ivor Lewis oesophagectomy. J Thorac Dis. 2019;11(Suppl 5): S786-93.

9. Hanyu Y, Qinglong D, Lixia L, et al. The comparison of ultrasound-guided thoracic paravertebral blockade and internal intercostal nerve block for non-intubated video-assisted thoracic surgery. J Thorac Dis. 2019;11:3476-81.

10. Wei K, Min S, Hao Y, et al. Postoperative analgesia after combined thoracoscopic-laparoscopic esophagectomy: a randomized comparison of continuous infusion and intermittent bolus thoracic epidural regimens. J Pain Res. 2019;12:29-37.

11. Hermanides J, Hollmann MW, Stevens MF, et al. Failed epidural: causes and management. $\mathrm{Br} \mathrm{J}$ Anaesth. 2012;109:144-54.

12. Christie IW, McCabe S. Major complications of epidural analgesia after surgery: results of a six-year survey. Anaesthesia. 2007;62:335-41.

13. Al-Rawi OY, Pennefather SH, Page RD, et al. The effect of thoracic epidural bupivacaine and an intravenous adrenaline infusion on gastric tube blood flow during esophagectomy. Anesth Analg. 2008;106:884-7.

14. Tang CL, Hu YD, Zhang ZT, et al. Dexmedetomidine with sufentanil in intravenous patientcontrolled analgesia for relief from postoperative pain, inflammation and delirium after esophageal cancer surgery. Biosci Rep. 2020;40(5): BSR20193410.

15. Katz P, Takyar S, Palmer P, et al. Sublingual, transdermal and intravenous patient-controlled analgesia for acute post-operative pain: systematic literature review and mixed treatment comparison. Curr Med Res Opin. 2017;33(5):899-910.

16. Chu LH, Zhang XL, Lu YP, et al. Improved analgesic effect of paravertebral blocks before and after videoassisted thoracic surgery: a prospective, doubleblinded, randomized controlled trial. Pain Res Manag. 2019. https://doi.org/10.1155/2019/ 9158653.

17. Poupore AK, Stem M, Molena D, et al. Incidence, reasons, and risk factors for read mission after surgery for benign distal esophageal disease. Surgery. 2016;160(3):599-606.

18. Ng CS, Hui JW, Wong RH. Minimizing single-port access in video-assisted wedge resection, with a hookwire. Asian Cardiovasc Thorac Ann. 2013;21(1):114-5.

19. Jamal $\mathrm{H}$, Ivan $\mathrm{U}$, Omar $\mathrm{V}$, et al. Utilization of erector spinae plane block in the chronic pain clinic for two patients with post-thoracotomy pain. Cureus. 2020;12:e8988.

20. Mowat I, Schneider F, GhorI A. Paravertebral blockade in thoracoscopic surgery. Eur J Cardiothorac Surg. 2012;42(2):390.

21. Niwa $Y$, Koike $M$, Torii $K$, et al. Combination of continuous paravertebral block and epidural anesthesia in postoperative pain control after esophagectomy. Esophagus. 2016;13:42-7.

22. Yeung JH, Gates S, Naidu BV, et al. Paravertebral block versus thoracic epidural for patients undergoing thoracotomy. Cochrane Database Syst Rev. 2016;2:CD009121.

23. Zhang S, Liu H, Cai H. Efficacy and safety of continuous paravertebral block after minimally invasive radical esophagectomy for esophageal cancer. Pain Res Manag. 2020. https://doi.org/10.1155/ 2020/3105874.

24. Kingma BF, Eshuis WJ, de Groot EM, et al. Paravertebral catheter versus epidural analgesia in minimally invasive esophageal resection: a randomized controlled multicenter trial (PEPMEN trial). BMC Cancer. 2020;20(1):142.

25. Preeyaphan A, Acksara R. General anesthesia with thoracic paravertebral block for modified radical mastectomy. J Med Assoc Thai. 2010;93(Suppl. 7): S149-53.

26. Gacio MF, Lousame AMA, Pereira S, et al. Paravertebral block for management of acute postoperative pain and intercostobrachial neuralgia in major breast surgery. Braz J Anesthesiol. 2016;66:475-84. 